Military Technical College

Kobry El-Kobbah,

Cairo, Egypt

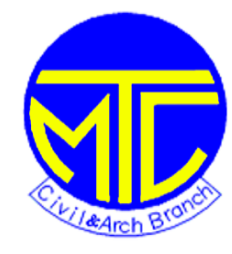

(n) $9^{\text {th }}$ International Conference
on Civil and Architecture

Engineering

ICCAE-9-2012

\title{
PROLIANCE - A Newer Generation of Program Management Software
}

\author{
Ahmed Kandil , ${ }^{*}$ MSCE, PE, PMP
}

\section{ABSTRACT}

Since eighties of the last century, several computerized program helped consultants and construction engineers manage their projects. Most of the software concentrated on time management through CPM techniques. Others covered document management or cost management. Yet, PROLIANCE provides time, cost, contract, file, and field and document management in addition to a very powerful reporting tool. Also Proliance is unique in that it covers the life cycle of the project from planning through operation. You can monitor a project, a program, a portfolio of programs through Proliance.

Through the presentation, audience will be able to realize the powerful features that Proliance software can offer to help them managing their projects or portfolios. We will discuss case study projects using this software either in USA or in the Gulf. Through a live demo, audience will be able to drill down on the program and explore the program in action.

Real life examples will be provided to help the audience link between real construction problems and the benefits from using a powerful software program. We will also discuss future trends and expected development.

\section{Key Words:}

CPM techniques, PROLIANCE, portfolios, live demo, document management, cost management, Project Life Cycle. 